\title{
A comparison of the analgesic efficacy of serratus anterior plane block vs. paravertebral nerve block for video-assisted thoracic surgery: a randomized controlled trial
}

\author{
Yi Zhang, Ze Fu, Te Fang, Kexin Wang, Zimeng Liu, Hongqing Li, Wenwen Jiang, Xuezhao Cao \\ Department of Anesthesiology, the First Hospital of China Medical University, Shenyang, Liaoning, China
}

Videosurgery Miniinv 2022; 17 (1): 134-142

DOI: https://doi.org/10.5114/wiitm.2021.105725

\begin{abstract}
Introduction: Patients who undergo video-assisted thoracic surgery (VATS) frequently experience moderate to severe postoperative pain. Serratus anterior plane block (SAPB) is a relatively novel technique that can block the lateral cutaneous branches of the intercostal nerves as well as the long thoracic nerve.

Aim: To evaluate the analgesic efficiency of deep serratus plane block (DSPB) and superficial serratus anterior plane block (SSPB) as well as paravertebral nerve block (PVB) in patients undergoing VATS.

Material and methods: $A$ total of 74 patients aged 16-80 undergoing VATS were randomized to receive either DSPB or SSPB as well as PVB. Ultrasound (US) guided DSPB or SSPB as well as PVB was performed preoperatively on the patients according to their groups. All patients were provided with patient-controlled intravenous analgesia (PCIA) for postoperative analgesia. The primary outcomes were the levels of postoperative pain at rest and on coughing evaluated by the visual analog scale (VAS), and intraoperative and postoperative opioid consumption. The secondary outcomes included PCIA pressing times, side effects and satisfaction with analgesia, duration of nerve block, intraoperative hemodynamic changes and vasoactive drug dosage.

Results: No significant differences of VAS score were found. During the operation, PVB reduced consumption of opioids $(27.23 \pm 5.10 \mathrm{mg})$ compared to DSPB $(31.20 \pm 3.80 \mathrm{mg})$ and SSPB $(32.61 \pm 5.28 \mathrm{mg})$. The effective pressing times of PCIA in the SSPB group $(0.18 \pm 0.65)$ were significantly lower compared to the PVB group $(1.09 \pm 1.50)$ at $12 \mathrm{~h}$ postoperatively. Accordingly, SSPB also reduced the dosage of PCIA $(26.55 \pm 4.72 \mathrm{ml})$ compared to PVB $(31.45 \pm 7.60 \mathrm{ml})$. Time of the PVB procedure was longer $(11.14 \pm 1.66 \mathrm{~min})$ than DSPB $(5.68 \pm 1.10 \mathrm{~min})$ and SSPB $(4.77 \pm 1.04 \mathrm{~min})$. Conclusions: DSPB and SSPB are easy to perform and can serve as a promising alternative technique to PVB that may offer comparable analgesic effectiveness for patients undergoing VATS.
\end{abstract}

Key words: postoperative pain, deep serratus plane block, superficial serratus anterior plane block, paravertebral nerve block, video-assisted thoracic surgery.

\section{Introduction}

Video-assisted thoracic surgery (VATS) is a standard surgical procedure for both minor and major oncological lung surgery. Over $85 \%$ patients undergoing VATS often suffer from moderate to severe postoperative pain when coughing and moving [1]. Furthermore, $22 \%$ to $63 \%$ are converted to chronic pain [2]. Uncontrolled postoperative pain, which is attributed to muscle incisions, rib retractions, and intercostal nerve damage, can result in respirato- 
ry complications such as hypoxia and atelectasis, which preclude early recovery $[3,4]$.

Effective analgesia can alleviate the pain of thoracic surgery, which is provided by thoracic epidural anesthesia (TEA), paravertebral block (PVB), erector spinae plane block (ESPB), serratus anterior plane block (SAPB) and venous analgesia [5]. TEA is the current gold-standard analgesia in thoracotomy. However, TEA has a 30\% failure rate, which carries the risk of epidural hematoma or abscess [6]. In recent years, PVB warrants greater attention with its advantages of small trauma, low coagulation requirements, hemodynamic stability and good analgesic effect $[7,8]$. However, PVB is not only technically difficult to perform especially in obese patients, but also could be less efficient after pleurodesis due to pleural inflammation or surgical dilaceration of the parietal lining of the pleura [9]. TEA and PVB exhibit certain difficulties with regard to their administration and side effects. Minimally invasive surgery might require less invasive analgesia. Therefore, the clinical standard minimally invasive analgesic technique for VATS is highly recommended.

SAPB, which is less difficult and has fewer severe complications, may be more suitable for VATS [10]. SAPB can completely cover the range of the long thoracic nerve as well as the lateral cutaneous branches of $\mathrm{T} 2$ to $\mathrm{T} 5$ intercostal nerves, and complement the deficiency of PVB, TEA, and selective intercostal nerve blocks [11]. It is simple to operate, not restricted to the patients who are obese or use anticoagulants, and also exhibited a satisfactory analgesic effect $[2,5,12,13]$. More recently, a single-center, double-blinded study with 40 patients showed that compared to PVB, SAPB was non-inferior in terms of 48-hour opioid consumption and was associated with improving functional measures in thoracic surgical patients [14]. SAPB can be performed at superficial or deep planes [15-17]. Blanco et al. showed that superficial serratus anterior plane block (SSPB) had a wider range and longer block time compared to deep serratus plane block (DSPB) [15]. Conversely, Piracha et al. found that DSPB could relieve the uncontrollable pain of SSPB [16]. However, whether DSPB and SSPB were as good as PVB remained unclear.

\section{Aim}

The aim of this study is to investigate the analgesic effectiveness of DSPB and SSPB for patients undergoing VATS and the potential for SAPB as an alternative to PVB for VATS.

\section{Material and methods}

This prospective, randomized controlled study was performed in Shenyang, after receiving the approval of the institutional ethical committee of the First Hospital of China Medical University and was registered in the Chinese Clinical Trials Registry (Registration No: ChiCTR1900024678). All patients were aged 16-80 years with ASA I or II scheduled for VATS. Patients were excluded as follows: (1) allergy to local anesthetics; (2) ASA III or IV; (3) severe obese patients (BMI > $\left.32 \mathrm{~kg} / \mathrm{m}^{2}\right)$; (4) motion sickness; severe cardiorespiratory, hepatic, renal disorders; chronic chest pain; (5) opioid abuse and inability to communicate. According to our preliminary study data, intraoperative opioid consumptions in DSPB, SSPB and PVB groups were $31.22 \mathrm{mg}, 34.71 \mathrm{mg}$ and $27.5 \mathrm{mg}$. 22 patients per group were required to achieve a significance level of 0.05 with a power of $80 \%$. The statistical test used for sample size calculation was one way ANOVA power analysis. Power calculation was completed using PASS (NCSS LLC, Kaysville, Utah). Finally, a total of 74 patients were recruited and provided their written informed consent to participate in this study. They were randomly assigned to receive either DSPB or SSPB as well as PVB.

Data were analyzed using GraphPad Prism 8. Continuous numerical variables were presented as the mean and standard deviation or standard error of the mean, categorical variables were presented as the ratio or as the number and percentage, and between-group differences were compared using Fisher's exact test (for nominal data) or the chi-squared test for a trend (for ordinal data). Primary and secondary endpoints for each analgesic technique used were compared using the Kruskal-Wallis test with Dunn's correction. The reported $p$-value is two-sided. $P<0.05$ was considered statistically significant. The Cochran-Armitage test was used for satisfaction score analysis.

\section{Intraoperative management}

On arrival in the operating room (OR), after routine ASA monitoring and arranging the patients in the lateral decubitus position with the operative side up, ultrasound-guided nerve block was performed. A $5 \mu \mathrm{g}$ dose of sufentanil was administered preemptively. 
In the DSPB group, a US probe was placed parallel to the midaxillary line at the level of T3-4 and moved laterally to visualize the rib, pleura, front serratus, and latissimus dorsi. A 100the mm blunttipped needle was advanced beneath the serratus anterior muscle. Then, saline $(1 \mathrm{ml})$ was injected to confirm the position followed by $20 \mathrm{ml}$ of $0.5 \%$ ropivacaine. In the SSPB group, the tip of the needle was advanced to the plane superficial to the serratus anterior muscle. Similarly, a total of $20 \mathrm{ml}$ of $0.5 \%$ ropivacaine was injected. In the PVB group, the US probe was placed parallel to the posterior midline at the level of T5 and moved laterally to visualize the transverse process and pleura. In the same way, $20 \mathrm{ml}$ of $0.5 \%$ ropivacaine was injected.

General anesthesia was induced after nerve block with propofol $2.0 \mathrm{mg} / \mathrm{kg}$, sufentanil $0.4 \mu \mathrm{g} / \mathrm{kg}$, cis-atracurium $0.15 \mathrm{mg} / \mathrm{kg}$ and dexamethasone $5 \mathrm{mg}$. Pharyngeal local anesthesia was performed with $3 \mathrm{ml}$ of $2 \%$ lidocaine and a double-lumen tube was intubated. The tidal volume $(6-8 \mathrm{ml} / \mathrm{kg})$ and the ventilatory frequency were adjusted to maintain an end-tidal carbon dioxide tension of 35-45 $\mathrm{mm} \mathrm{Hg}$ and airway pressure below $30 \mathrm{~cm} \mathrm{H}_{2} \mathrm{O}$. Anesthesia was maintained with $2 \%$ propofol $(30 \mathrm{ml} / \mathrm{h}$ ) and sevoflurane (0.7-1.5\%) to maintain a bispectral index of 40-60. Hypertension was treated with oxycodone hydrochloride $2 \mathrm{mg}$ or Ebrantil $5 \mathrm{mg}$, oxycodone hydrochloride was used to block sympathetic response to pain. Hypotension was treated with ephedrine $6 \mathrm{mg}$ or phenylephrine $0.1 \mathrm{mg}$. Bradycardia was treated with atropine $0.3 \mathrm{mg}$. At the end of the surgery, tropisetron $5 \mathrm{mg}$ was given intravenously to prevent postoperative nausea and vomiting. All patients were transferred to a post-anesthesia care unit (PACU) after surgery. Postoperative analgesia was followed by patient-controlled intravenous analgesia (PCIA). The PCIA regimen consisted of hydromorphone $14 \mathrm{mg}$ mixed with normal saline to a total volume of $150 \mathrm{ml}$. The disposable PCIA device was set to background infusion of $2 \mathrm{ml} / \mathrm{h}$, demand bolus $6 \mathrm{ml}$ and a 10-min lockout. If patients reported a visual analogue score (VAS score) $\geq 4$, flurbiprofen axetil $100 \mathrm{mg}$ was administered every $12 \mathrm{~h}$ as a rescue analgesia. If severe nausea or vomiting occurs, we treated the patients with $5 \mathrm{mg}$ tropisetron or stopped PCIA temporarily. After these symptoms reversed, the $\mathrm{PCIA}$ restarted.

The primary outcomes were postoperative VAS score, and intraoperative and postoperative opioid consumption. The secondary outcomes included PCIA pressing times, side effects, satisfaction with analgesia, duration of operating nerve block, intraoperative hemodynamic changes and vasoactive drug consumption. VAS scores at rest and on coughing were collected at $12 \mathrm{~h}, 24 \mathrm{~h}, 48 \mathrm{~h}$ and $72 \mathrm{~h}$ postoperatively. The different types of opioids were converted to IV morphine equivalents using the GlobalRPh morphine equivalence calculator at http://www. globalrph.com. Effective and ineffective PCIA pressing times were collected at $12 \mathrm{~h}, 24 \mathrm{~h}, 48 \mathrm{~h}$ and $72 \mathrm{~h}$ postoperatively. The dosage of PCIA was also recorded at the same time. Satisfaction with analgesia in the first 72 postoperative hours was divided into five grades, "highly unsatisfactory", "unsatisfactory", "neutral”, "satisfactory", "highly satisfactory". Intraoperative hemodynamic changes recorded were the blood pressure and heart rate when the patients entered the OR, before the operation, 5 min after surgical incision, before endotracheal extubation, 5 min after extubation and before leaving the PACU, as well as the duration of intraoperative hypotension. All of the outcomes and perioperative data were collected by an investigator who was blinded to the group allocation.

\section{Results}

\section{Patient characteristics}

Seventy-four patients were enrolled in the study; 8 were excluded: 1 for VATS conversion to thoracotomy, 1 for secondary thoracotomy on the next day, 6 for stopping using PCIA due to severe nausea and vomiting (3 in SSPB group, 2 in DSPB group, 1 in PVB group). Ultimately, a total of 66 patients completed the study; each group included 22 patients, which is shown in Figure 1. The demographic data, ASA classes, personal history, medical history, and duration of the surgery of the study patients are summarized in Table I. There was no significant difference with respect to the demographic data $(p>0.05)$.

\section{Postoperative VAS score}

There were no significant differences of VAS scores at rest and on coughing among the three groups at 12 h, 24 h, 48 h, and 72 h postoperatively (Table II). None of the patients suffered severe pain. During the first $24 \mathrm{~h}$ postoperatively, the patients presented with mild to moderate pain when coughing (13 in DSPB 
group, 13 in SSPB group and 17 in PVB group). During the rest of the time, they presented with mild pain.

\section{Intraoperative dosage of opioids}

Sufentanil and oxycodone hydrochloride were converted to morphine, and the consumption was compared in the three groups. In intergroup comparisons, the PVB group $(27.23 \pm 5.10 \mathrm{mg})$ was associated with reducing intraoperative opioid consumption compared to the DSPB $(31.20 \pm 3.80 \mathrm{mg})$ and SSPB group (32.61 $\pm 5.28 \mathrm{mg}, p<0.05$ ). Therefore, PVB had a better analgesic effect than DSPB and SSPB during the operation.

\section{PCIA pressing times and dosage of postoperative analgesics}

PCIA pressing times included effective and ineffective times (Table III). During postoperative hours $0-12$, there were statistically significant differences for effective pressing times in the DSPB group (1.23 $\pm 1.31)$, SSPB group $(0.77 \pm 1.00)$ and PVB group (2.05 $\pm 1.64)(p<0.05)$. Moreover, the pressing time in the SSPB group was significantly lower compared to the PVB group $(p<0.05)$. There was no significant difference in ineffective PCIA pressing times.

Postoperative analgesics included PCIA and flurbiprofen axetil. In the first $12 \mathrm{~h}$ postoperatively, the SSPB group had significantly lower PCIA dosage compared with the PVB group $(p<0.05)$. The maxi-

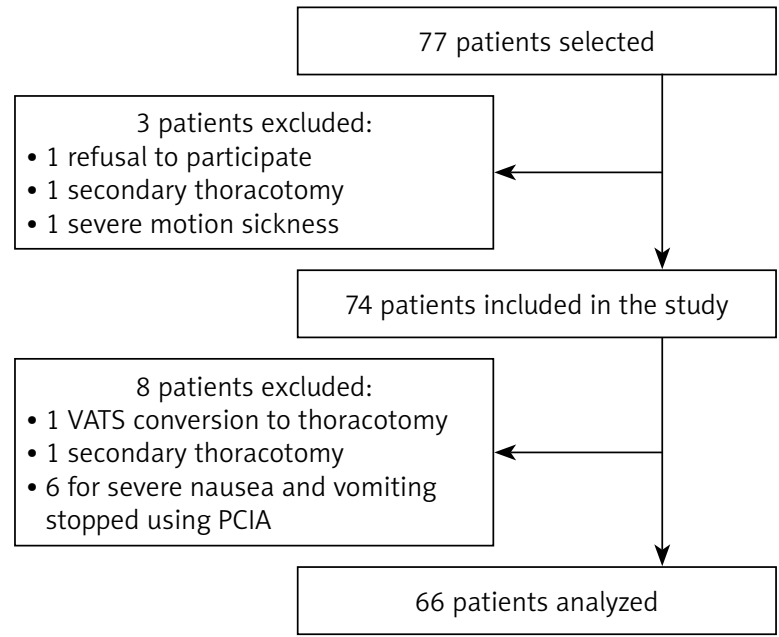

Figure 1. Flow diagram of the study

mum dose of flurbiprofen axetil is $100 \mathrm{mg}$ every $12 \mathrm{~h}$. In this study, a maximum of $300 \mathrm{mg}$ was given, which happened in the SSPB group. They was no significant difference in average consumption among the three groups.

\section{Satisfaction with analgesia}

There were no significant differences in satisfaction with analgesia in the three groups. Both DSPB and SSPB, as well as PVB, could provide a good analgesic effect postoperatively; eighty percent of the patients showed "neutral" and "satisfactory" approximately. Patients in the PVB group showed more

Table I. Demographic data of 22 patients for each group

\begin{tabular}{|c|c|c|c|c|}
\hline Parameter & DSPB group & SSPB group & PVB group & $P$-value \\
\hline Age [years] mean \pm SD & $55 \pm 12.53$ & $57.95 \pm 7.65$ & $58.64 \pm 6.78$ & 0.514 \\
\hline Gender (male) $n(\%)$ & $14(63.64)$ & $11(50)$ & $8(36.36)$ & 0.195 \\
\hline $\mathrm{BMI}\left[\mathrm{kg} / \mathrm{m}^{2}\right]$ & $23.11 \pm 2.90$ & $24.40 \pm 2.01$ & $23.79 \pm 2.72$ & 0.275 \\
\hline ASA I $(n)$ & 14 & 10 & 12 & \\
\hline ASA $\|(n)$ & 6 & 11 & 10 & \\
\hline ASA III $(n)$ & 2 & 1 & 0 & 0.377 \\
\hline Smoking $(n)$ & 7 & 9 & 7 & 0.766 \\
\hline Drinking $(n)$ & 8 & 7 & 4 & 0.383 \\
\hline Hypertension (n) & 5 & 8 & 8 & 0.533 \\
\hline Diabetes mellitus ( $n$ ) & 1 & 3 & 2 & 0.577 \\
\hline Coronary mellitus ( $n$ ) & 1 & 1 & 3 & 0.421 \\
\hline History of surgery (n) & 6 & 7 & 6 & 0.929 \\
\hline Duration of surgery [min] & $130.82 \pm 70.28$ & $143.18 \pm 90.23$ & $105.32 \pm 37.98$ & 0.221 \\
\hline
\end{tabular}

Values of age, BMI and duration of surgery are expressed as mean \pm standard deviation. 
Table II. Postoperative VAS scores at rest and on coughing

\begin{tabular}{|c|c|c|c|c|c|c|c|}
\hline VAS & DSPB group & SSPB group & PVB group & $P$-value & $\begin{array}{l}P \text { for DSPB } \\
\text { group versus } \\
\text { SSPB group }\end{array}$ & $\begin{array}{l}P \text { for DSPB } \\
\text { group versus } \\
\text { PVB group }\end{array}$ & $\begin{array}{l}P \text { for SSPB } \\
\text { group versus } \\
\text { PVB group }\end{array}$ \\
\hline \multicolumn{8}{|l|}{ VAS-R: } \\
\hline $12 \mathrm{~h}$ & $1.3[0.8,1.8]$ & $1.6[0.8,2.4]$ & $1.5[0.6,2.4]$ & 0.240 & 0.282 & 0.606 & 0.834 \\
\hline $24 \mathrm{~h}$ & $1.1[0.4,1.8]$ & $1.0[0.3,1.7]$ & $1.3[0.7,19]$ & 0.297 & 0.797 & 0.669 & 0297 \\
\hline $48 \mathrm{~h}$ & $0.4[0.0,0.9]$ & $0.3[0.0,0.9]$ & $0.5[0.0,1.1]$ & 0.662 & 0.960 & 0.850 & 0.694 \\
\hline $72 \mathrm{~h}$ & $0.0[110,0.0]$ & $0.0[0.0,0.0]$ & $0.1[0.0,0.4]$ & 0.131 & $>0.999$ & 0.186 & 0.186 \\
\hline \multicolumn{8}{|l|}{ VAS-C: } \\
\hline $12 \mathrm{~h}$ & $3.5[2.8,42]$ & $3.8[3.0,4.6]$ & $3.8[2.9,4.7]$ & 0.305 & 0.410 & 0.314 & 0.982 \\
\hline $24 \mathrm{~h}$ & $2.9[13,4.1]$ & $3.0[2.2,3.8]$ & $3.3[2.7,3.9]$ & 0.304 & 0.939 & 0.218 & 0.374 \\
\hline $48 \mathrm{~h}$ & $1.6[0.5,2.7]$ & $1.7[1.0,2.4]$ & $2.2[1.5,2.9]$ & 0.051 & 0.936 & 0.069 & 0.143 \\
\hline $72 \mathrm{~h}$ & $0.5[0.0,1.0]$ & $0.5[0.0,1.1]$ & $0.9[0.2,1.6]$ & 0.165 & 0.967 & 0.127 & 0.204 \\
\hline
\end{tabular}

Values are expressed as the mean [95\% confidence interval]. When the lower limit value of the 95\% confidence interval is less than 0, 0 is used instead. $V A S-R$ - values of VAS scores at rest, VAS-C - values of VAS scores on coughing.

Table III. Postoperative analgesics

\begin{tabular}{|c|c|c|c|c|c|c|c|}
\hline VAS & DSPB group & SSPB group & PVB group & $P$-value & $\begin{array}{l}P \text { for DSPB } \\
\text { group versus } \\
\text { SSPB group }\end{array}$ & $\begin{array}{l}P \text { for DSPB } \\
\text { group versus } \\
\text { PVB group }\end{array}$ & $\begin{array}{l}P \text { for SSPB } \\
\text { group versus } \\
\text { PVB group }\end{array}$ \\
\hline \multicolumn{8}{|l|}{ Effective times: } \\
\hline $0-12 \mathrm{~h}$ & $1.23 \pm 1.31$ & $0.77 \pm 1.00$ & $2.05 \pm 1.64$ & $0.012^{*}$ & 0.519 & 0.126 & $0.009^{*}$ \\
\hline $12-24 \mathrm{~h}$ & $1.86 \pm 2.68$ & $1.09 \pm 1.93$ & $2.00 \pm 2.20$ & 0.131 & 0.522 & 0.980 & 0.408 \\
\hline $24-48 \mathrm{~h}$ & $0.72 \pm 1.32$ & $0.36 \pm 0.77$ & $1.09 \pm 1.50$ & 0.210 & 0.320 & 0.599 & 0.320 \\
\hline $48-72 \mathrm{~h}$ & 0 & 0 & $0.05 \pm 0.21$ & 0.368 & $>0.999$ & 0.443 & 0.443 \\
\hline \multicolumn{8}{|c|}{ Dosage of PCIA [ml]: } \\
\hline $0-12 \mathrm{~h}$ & $27.86 \pm 6.92$ & $26.55 \pm 4.72$ & $31.45 \pm 7.60$ & $0.024^{*}$ & 0.791 & 0.184 & $0.046^{\star}$ \\
\hline $12-24 \mathrm{~h}$ & $27.77 \pm 9.28$ & $30.18 \pm 11.81$ & $34.64 \pm 15.91$ & 0.811 & 0.492 & 0.191 & 0.492 \\
\hline $24-48 \mathrm{~h}$ & $49.95 \pm 10.62$ & $48.91 \pm 4.03$ & $52.68 \pm 15.70$ & 0.788 & 0.951 & 0.711 & 0.522 \\
\hline $48-72 \mathrm{~h}$ & $33.14 \pm 14.98$ & $39.73 \pm 12.58$ & $40.68 \pm 17.52$ & 0.023 & 0.343 & 0.248 & 0.977 \\
\hline \multicolumn{8}{|l|}{ Postoperative: } \\
\hline $\begin{array}{l}\text { Flurbiprofen } \\
\text { Axetil [mg] }\end{array}$ & $59.09 \pm 77.81$ & $54.55 \pm 72.16$ & $72.73 \pm 80.80$ & 0.744 & 0.980 & 0.835 & 0.726 \\
\hline
\end{tabular}

*Significant difference.

"highly unsatisfactory" and "neutral" than in the DSPB group and the SSPB group.

\section{Side effects}

No patient exhibited block-related complications, such as urinary retention, pneumonia, local anesthetic toxicity, bleeding, or infection. The side effects of opi- oids including nausea, vomiting and dizziness showed no significant differences among the three groups.

\section{Duration of operating nerve block}

The duration of operating nerve block, recorded from disinfection to nerve block needle extraction, in all of the groups was done once by the same ex- 
perienced anesthesiologist. Durations of the DSPB (5.77 $\pm 1.20 \mathrm{~min})$ and SSPB group (4.77 $\pm 1.04 \mathrm{~min})$ were significantly shorter than that of the PVB group $(11.14 \pm 1.66 \mathrm{~min}, p<0.05)$. PVB was more complex for the anesthesiologist to operate.

\section{Intraoperative hemodynamic changes and dosage of vasoactive drugs}

Intraoperative blood pressure changes were shown with mean arterial pressure (MAP), which was compared at six time points (Figure 2). At 5 min after the operation, MAP was lower in the PVB group (85.45 $\pm 16 \mathrm{~mm} \mathrm{Hg})$ than in the DSPB $(99.21 \pm 15.27 \mathrm{~mm} \mathrm{Hg}$ $p<0.05)$ and SSPB group (104.70 $\pm 16.33 \mathrm{~mm} \mathrm{Hg}$, $p<0.05)$. At 5 min after extubation and before leaving the PACU, the DSPB group showed lower MAP than the SSPB group $(p<0.05)$. The three groups were comparable regarding the changes of heart rate (Figure 3 ) and the duration of intraoperative hypotension, which showed no significant differences $(p>0.05)$.

Vasoactive drugs included ephedrine, atropine and phenylephrine (Table IV). In-group analyses showed that PVB $(0.14 \pm 0.24 \mathrm{mg})$ was associated with more intraoperative atropine consumption than DSPB (0 mg, $p<0.05)$. However, there were no differences in ephedrine and phenylephrine consumption.

\section{Discussion}

This randomized, double-blind study demonstrated that DSPB, SSPB or PVB combined with PCIA reduced the postoperative pain and showed similar satisfaction with analgesia in patients undergoing VATS. Intraoperative opioid consumption remained significantly lower in PVB. SSPB showed lower PCIA pressing times and $\mathrm{PCIA}$ dosage than $\mathrm{PVB}$. Furthermore, DSPB and SSPB were easy for the anesthetist to operate, with significantly lower operating duration than PVB. PVB was associated with maintaining hemodynamic stability. However, PVB consumed more atropine intraoperatively.

There were different opinions about the postoperative analgesic effect of DSPB, SSPB and PVB. PVB has long been considered the best possible choice for postoperative analgesia of VATS [18]. In recent studies, SSPB proponents have described successful analgesia without the potentially hazardous

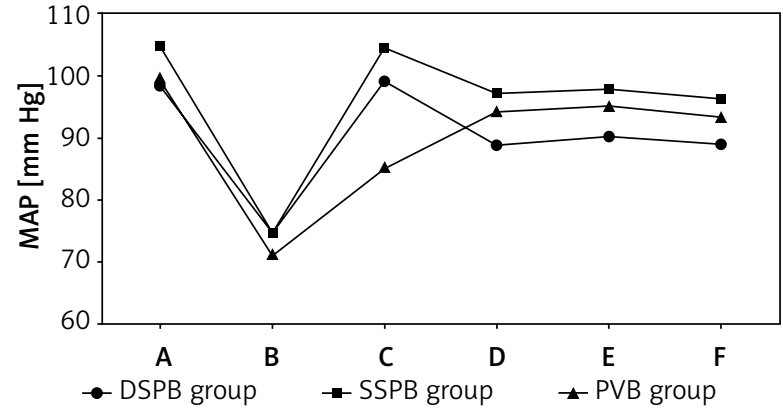

Figure 2. Intraoperative MAP changes: $A-O R$ admission, $\mathrm{B}$ - before operation, $\mathrm{C}-5 \mathrm{~min}$ after operation, $D$ - before extubation, $E-5$ min after extubation, F - after leaving PACU

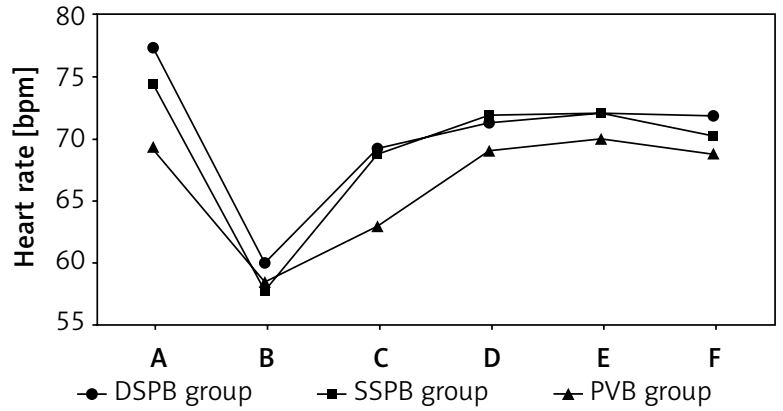

Figure 3. Intraoperative heart rate changes: $A-O R$ admission, $B$ - before operation, $C-5$ min after operation, $D$ - before extubation, $E-5$ min after extubation, $\mathrm{F}$ - after leaving PACU

Table IV. Intraoperative consumption of vasoactive drugs

\begin{tabular}{|lccccccc|}
\hline VAS & DSPB group & SSPB group & PVB group & $P$-value & $\begin{array}{c}P \text { for DSPB } \\
\text { group versus } \\
\text { SSPB group }\end{array}$ & $\begin{array}{c}P \text { for DSPB } \\
\text { group versus }\end{array}$ & $\begin{array}{c}P \text { for SSPB } \\
\text { group versus } \\
\text { PVB group }\end{array}$ \\
\hline Ephedrine $[\mathrm{mg}]$ & $1.91 \pm 4.57$ & $1.09 \pm 2.94$ & $1.50 \pm 4.02$ & 0.879 & 0.776 & 0.938 & 0.938 \\
\hline Atropine $[\mathrm{mg}]$ & 0 & $0.05 \pm 0.21$ & $0.14 \pm 0.24$ & $0.003^{*}$ & 0.708 & $0.043^{*}$ & 0.225 \\
\hline $\begin{array}{l}\text { Phenylephrine } \\
{[\mathrm{mg}]}\end{array}$ & $0.33 \pm 0.73$ & $0.10 \pm 0.32$ & $0.33 \pm 0.57$ & 0.196 & 0.407 & $>0.999$ & 0.393 \\
\hline
\end{tabular}

*Significant difference. 
need for advancing the needle deeper toward the pleura $[15,17]$. However, anatomy arguably favored DSPB, as injection in the fascial plane below the serratus muscle, which blocks the lateral cutaneous branches of the intercostal nerves, might show a better analgesic effect [19]. In our study, DSPB, SSPB and PVB showed similar postoperative analgesic effects, and most patients were satisfied with the analgesic effect. All three can be used for postoperative analgesia of VATS. However, in the early postoperative period (12 h), the SSPB group provided superior pain relief with significantly lower effective PCIA pressing times and dosage compared to the PVB group. Some studies showed that the duration of the sensory blockade produced by SSPB and DSPB was $730-780 \mathrm{~min}$ and $380-400 \mathrm{~min}$ respectively [20-22]. The effective time of PVB persisted for $48 \mathrm{~h}$ postoperatively [23]. In our study, the duration of postoperative analgesia for PVB was shorter, probably due to the pharmacological properties of ropivacaine.

During the operation, compared with DSPB and SSPB, PVB showed a superior analgesic effect. PVB significantly decreased intraoperative consumption of opioids compared to DSPB and SSPB, which indicated that the short-term analgesic effect of PVB was better than that of DSPB and SSPB. These findings support observations from previous reports that showed the effectiveness of PVB [24].

The ideal analgesic techniques should not only have a perfect analgesia effect, but also have the advantages of a simple operation, accurate control, high success rate and few complications. The puncture duration of PVB was significantly longer than that of DSPB and SSPB in our study. It might be related to the difference of anatomical position. The serratus anterior muscle was superficial, and could be scanned by a high-frequency linear array ultrasound probe to easily obtain clear images of the serratus anterior muscle and its neighbors. During the puncture, the angle between the needle and skin was small, so the puncture needle could be imaged clearly [25]. Richardson et al. also found that the deep fascia of the serratus anterior muscle had poor adhesion to the intercostal external muscles and was easier to separate than the superficial plane of the serratus anterior muscle, which was also found in our study [26]. The location of the thoracic paravertebral nerve was deeper and should be scanned with a low-frequency convex ar- ray probe or high-frequency linear array probe. The puncture needle was difficult to image due to the large angle.

A few studies have shown that the analgesia effect of SSPB was similar to an epidural but perhaps with less hemodynamic instability [17]. In our study, both DSPB and SSPB, as well as PVB, could maintain hemodynamic stability. However, PVB consumed more atropine intraoperatively. Previous studies also have shown that PVB can cause the occurrence of bradycardia and hypotension with a rate of $0.47-2.2 \%$, which might be related to sympathetic block [27].

In addition, the incidence of side effects did not show significant differences among the three groups. There were 6 patients who had motion sickness and reported severe nausea and vomiting. After stopping PCIA, the side effects disappeared, which indicated that they might be associated with the opioid. They withdrew from our study on the basis of the exclusion criteria. We did not observe any complication associated with nerve block, but pneumothorax was potential. The deep surface of the paravertebral area was the pleura, and there was a risk of puncture of the pleura, pneumothorax and other complications. Naja et al. performed PVB in 662 patients, and the probability of developing pneumothorax was about $0.5 \%$ [28]. Richardson's study showed that PVB punctures occasionally entered the epidural space or punctured the pleura, and had a transient occurrence of Horner syndrome [26]. This could explain why many clinicians are reluctant to operate PVB in daily work. Accordingly, patients with a narrow intercostal space, obesity, or poor coagulation function should use DSPB or SSPB.

The present study had several limitations. First, as an observational study, our conclusions might have been limited by inadequate data collection. The pain of the nerve block procedure was not recorded. Meanwhile, due to the time limitation of preoperative preparation, we could only confirm the diffusion of local anesthetics by ultrasound, but did not collect the data of the spread level of analgesia. Second, the research subjects recruited to this study were not treated by the same surgeon, and there were uncontrollable differences. Third, it should be noted that during the operation, when surgeons cut open the skin and subcutaneous tissue of patients who received DSPB or SSPB, it showed a slight edema of subcutaneous tissue, which indicated the pos- 
sible loss of local anesthetics. Finally, this study did not explore the appropriate local anesthetic dose for nerve block. A study showed that methods of placing a paravertebral catheter (PVC) or an intercostal catheter (ICC) in the sub-pleural space, followed by an infusion pump, were safe and effective analgesic techniques to reduce postoperative pain [29]. In the future, we will conduct further research on the DSPB catheter and SSPB catheter.

\section{Conclusions}

DSPB, SSPB or PVB combined with PCIA could provide good postoperative analgesia for patients undergoing VATS. PVB showed a better analgesic effect than DSPB and SSPB intraoperatively. However, the operation of PVB was complex and had potential complications. DSPB or SSPB can serve as a promising alternative to PVB in optimal perioperative pain management in VATS. In future research, largescale prospective randomized controlled trials are required to compare the efficacy of postoperative analgesia by continuous infusion through a catheter.

\section{Conflict of interest}

The authors declare no conflict of interest.

\section{References}

1. Semyonov M, Fedorina E, Grinshpun J, et al. Ultrasound-guided serratus anterior plane block for analgesia after thoracic surgery. J Pain Res 2019; 12: 953-60.

2. Okmen K, Okmen BM. Evaluation of the effect of serratus anterior plane block for pain treatment after video-assisted thoracoscopic surgery. Anaesth Crit Care Pain Med 2018; 37: 349-53.

3. Ochroch EA, Gottschalk A. Impact of acute pain and its management for thoracic surgical patients. Thorac Surg Clin 2005; 15: 105-21.

4. Ochroch EA, Gottschalk A, Augostides J, et al. Long-term pain and activity during recovery from major thoracotomy using thoracic epidural analgesia. Anesthesiology 2002; 97: 1234-44.

5. Park MH, Kim JA, Ahn HJ, et al. A randomised trial of serratus anterior plane block for analgesia after thoracoscopic surgery. Anaesthesia 2018; 73: 1260-4.

6. Rosero EB, Joshi GP. Nationwide incidence of serious complications of epidural analgesia in the United States. Acta Anaesthesiol Scand 2016; 60: 810-20.

7. Hiro K, Sugiyama T, Kurata M, et al. Postoperative analgesia for video-assisted thoracoscopic surgery--continuous intravenous infusion of fentanyl combined with intercostal nerve block v.s. continuous epidural analgesia. Masui 2016; 65: 114-8.

8. Scarci M, Joshi A, Attia R. In patients undergoing thoracic surgery is paravertebral block as effective as epidural analgesia for pain management? Interact Cardiovasc Thorac Surg 2010; 10: 92-6.
9. Allain PA, Carella M, Agrafiotis AC, et al. Comparison of several methods for pain management after video-assisted thoracic surgery for pneumothorax: an observational study. BMC Anesthesiol 2019; 19: 120.

10. Tighe SQ, Karmakar MK. Serratus plane block: do we need to learn another technique for thoracic wall blockade? Anaesthesia 2013; 68: 1103-6.

11. Chu GM, Jarvis GC. Serratus anterior plane block to address postthoracotomy and chest tube-related pain: a report on 3 cases. A A Case Rep 2017; 8: 322-5.

12. Corso RM, Piraccini E, Byrne H, et al. The serratus anterior plane block for pediatric non-intubated video-assisted thoracoscopic surgery. Minerva Anestesiol 2017; 83: 775-6.

13. Kim DH, Oh YJ, Lee JG, et al. Efficacy of ultrasound-guided serratus plane block on postoperative quality of recovery and analgesia after video-assisted thoracic surgery: a randomized, triple-blind, placebo-controlled study. Anesth Analg 2018; 126: 1353-61.

14. Hanley C, Wall T, Bukowska I, et al. Ultrasound-guided continuous deep serratus anterior plane block versus continuous thoracic paravertebral block for perioperative analgesia in videoscopic-assisted thoracic surgery. Eur J Pain 2020; 24: 828-38.

15. Blanco R, Parras T, McDonnell JG, et al. Serratus plane block: a novel ultrasound-guided thoracic wall nerve block. Anaesthesia 2013; 68: 1107-13.

16. Piracha MM, Thorp SL, Puttanniah V, et al. "A tale of two planes": deep versus superficial serratus plane block for postmastectomy pain syndrome. Reg Anesth Pain Med 2017; 42: 259-62.

17. Khalil AE, Abdallah NM, Bashandy GM, et al. Ultrasound-guided serratus anterior plane block versus thoracic epidural analgesia for thoracotomy pain. J Cardiothorac Vasc Anesth 2017; 31: 152-8.

18. Steinthorsdottir KJ, Wildgaard L, Hansen HJ, et al. Regional analgesia for video-assisted thoracic surgery: a systematic review. Eur J Cardiothorac Surg 2014; 45: 959-66.

19. Mayes J, Davison E, Panahi P, et al. An anatomical evaluation of the serratus anterior plane block. Anaesthesia 2016; 71: 1064-9.

20. Bhoi D, Pushparajan HK, Talawar P, et al. Serratus anterior plane block for breast surgery in a morbidly obese patient. J Clin Anesth 2016; 33: 500-1.

21. López-Matamala B, Fajardo M, Estébanez-Montiel B, et al. A new thoracic interfascial plane block as anesthesia for difficult weaning due to ribcage pain in critically ill patients. Med Intensiva 2014; 38: 463-5.

22. Madabushi R, Tewari S, Gautam SK, et al. Serratus anterior plane block: a new analgesic technique for post-thoracotomy pain. Pain Physician 2015; 18: E421-4.

23. Vogt A, Stieger DS, Theurillat C, Curatolo M. Single-injection thoracic paravertebral block for postoperative pain treatment after thoracoscopic surgery. Br J Anaesth 2005; 95: 816-21.

24. Chalam KS, Patnaik SS, Sunil C, et al. Comparative study of ultrasound-guided paravertebral block with ropivacaine versus bupivacaine for post-operative pain relief in children undergoing thoracotomy for patent ductus arteriosus ligation surgery. Indian J Anaesth 2015; 59: 493-8.

25. Ueshima H, Iwamoto W, Otake H. Serratus plane block for a contraction of the latissimus dorsi muscle. Reg Anesth Pain Med 2016; 41: 411. 
26. Richardson J, Lönnqvist PA, Naja Z. Bilateral thoracic paravertebral block: potential and practice. Br J Anaesth 2011; 106 164-71.

27. Pace MM, Sharma B, Anderson-Dam J, et al. Ultrasound-guided thoracic paravertebral blockade: a retrospective study of the incidence of complications. Anesth Analg 2016; 122: 1186-91.

28. Naja Z, Lönnqvist PA. Somatic paravertebral nerve blockade. Incidence of failed block and complications. Anaesthesia 2001; 56: 1184-8.

29. Ma H, Song X, Li J, et al. Postoperative pain control with continuous paravertebral nerve block and intercostal nerve block after two-port video-assisted thoracic surgery. Videosurgery Miniinv 2021; 16: 273-81.

Received: 2.02.2021, accepted: 27.03.2021 